\title{
MATHEMATICAL MODEL OF INTERACTION BETWEEN SHARE WORKING BODY AND BEET ROOT DURING VIBRATIONAL DIGGING
}

\author{
Volodymyr Bulgakov $^{1}$, Semjons Ivanovs ${ }^{2}$, Ivan Holovach ${ }^{1}$, Yevhen Ihnatiev ${ }^{3}$ \\ ${ }^{1}$ National University of Life and Environmental Sciences of Ukraine, Ukraine; \\ ${ }^{2}$ Latvia University of Life Sciences and Technologies, Latvia; \\ ${ }^{3}$ Tavria State Agrotechnological University, Ukraine \\ semjons@apollo.lv
}

\begin{abstract}
Increasing the yield and quality of harvesting sugar beet by a vibrational digging tool is an urgent problem in the field of beet growing. As a result of the performed research an equivalent diagram of the force interaction of the beet root with the working surfaces of the vibrational digging tool was drawn up, and a new computational mathematical model of vibrational extraction of the beet root from the soil was built. The solution of the obtained system of differential equations on a PC made it possible to construct the main graphic dependencies between the design and the kinematic parameters of a particular technological process. As a result, new analytical dependences of the motion of the root crop in time in the direction of the forward movement of the vibrational digging tool were obtained, taking into account its design and kinematic parameters. With the help of the PC, the dependences of the movement of the root crop in time were constructed, when it moves vertically upwards during the process of complete extraction from the soil, also taking into account the specified parameters of the digging tool. Calculations showed that the time for complete extraction of the beet roots from the soil is $0.032 \mathrm{~s}$, which is essential for compliance with the conditions for the high-quality implementation of this process and high efficiency. The subsequent experimental investigations confirmed the achievement of the taken research goal.
\end{abstract}

Keywords: beet, root crop, soil, vibrational extraction, parameters.

\section{Introduction}

Sugar beet is the main source of sugar in Europe, and it covers a significant amount of agricultural areas $[1 ; 2]$. Harvesting of sugar beet is the most labour-intensive and expensive process in the production technology $[3 ; 4]$. Therefore, improvement of machines for harvesting sugar beet is an urgent task. Application of vibrational digging tools in modern beet-harvesting machines has become widespread in many countries of the world $[3 ; 5-7]$. This is due to their significantly lower traction resistance when moving in the soil at a set travel depth, the ability to extract beet roots from the soil without virtually any damage or loss. In addition, during vibrational digging from the lateral surface of beet roots, the adhered soil is shaken off more intensively, i.e., in fact, when extracted from the soil, they are intensively cleaned of the adhered soil. As a result, this provides a sufficiently high level of harvesting quality of sugar beet roots. The search for ways of further improvement of the vibrational digging process of the beet root crops and determination of rational design and kinematic parameters of the vibratory digging tools is an urgent task in the field of beet growing.

Theoretical and experimental studies of vibrational extraction of sugar beet roots have been treated in [5-7], in which the beet root is modelled as a body that has elastic properties and it is presented as a rod of variable cross-section with one lower fixed end. Besides, the transverse oscillations of this rod are analysed analytically and described using a fourth-order partial differential equation. However, the technological process itself of direct extraction of the beet roots from the soil, when the vibrational forces are applied to it, is not considered here, but it is only indicated that this issue can be solved with the help of additionally compiled kinetostatics equations. Besides, in this paper conditions are considered for the extraction of the beet roots from the soil under the impact of a disturbing force, which is applied in a transverse-horizontal plan. The authors of this work believe that it is this direction of oscillations that will most of all contribute to high-quality digging of the sugar beet roots from the soil. However, as practice has shown, the use of exactly the direction of vibration of the digging tools in a transverse-horizontal plane does not provide the necessary conditions for productivity and quality, which made it necessary to completely eliminate such oscillations. The following numerous theoretical and experimental investigations and design developments have shown that only the creation of oscillatory impacts upon the beet root bodies, which are in the soil exactly in a longitudinal-vertical plane, is the only possible way to further improvement of this technological process [8-11]. 
There are other published works in which the interaction process of the vibrational surfaces of the digging tool with the sugar beet body is investigated in detail, and the differential equations are drawn up for the movement of a cone-shaped beet body inside the digging tool. However, no investigations of the time of direct extraction of beet roots from the soil are given there.

The purpose of this investigation is determination of the conditions for high-quality extraction of beet roots from the soil and the choice of rational constructive and kinematic parameters of the ploughshare digging tools performing oscillations in a longitudinal-vertical plane.

\section{Materials and methods}

To solve this problem, we will analytically consider the process of extracting the sugar beet roots from the soil with a ploughshare digging tool, which, under the action of a vertical harmonic disturbing force, performs oscillations that are transmitted to the ploughshare from the vibrational drive mechanism.

We will begin the construction of a mathematical model of the interaction between the ploughshare digging tool and the beet root by drawing up an equivalent scheme [12]. In this case it is necessary to consider the interaction of the beet root body with the working surfaces of the vibratory digging tool, i.e. with its two ploughshares, which at the same time perform oscillatory movements in a longitudinalvertical plane. For this purpose we will imagine that the vibratory ploughshare digging tool has a form of two wedges (ploughshares) $A_{1} B_{1} C_{1}$ and $A_{2} B_{2} C_{2}$, each of them having inclinations at angles $\alpha, \beta, \gamma$ in space, and which are installed in such a way to relation to each other that there is formed a digging channel, the rear part of which narrows (Fig. 1). These wedges perform an oscillatory movement in a longitudinal-vertical plane (shown by arrows), and the direction of the forward movement of this vibrational digging tool is also shown by an arrow. In the middle of the space between these wedges there is a beet root, which is approximated by a cone-shaped body. With this vibrational digging tool we connect a rectangular Cartesian coordinate system $O x y z$, the centre $O$ of which is in the middle of the narrowed channel of the digger, the axis $O x$ coincides with the direction of the forward movement of the tool, the $O z$ axis is directed vertically upward, and the axis $O y$ is directed to the right side along the path of the tool. At such arrangement of the coordinate axes the projections of the upper points of each of the wedges $B_{1}$ and $B_{2}$ onto the axis $O y$ are denoted by the points $O_{1}$ and $O_{2}$, respectively.

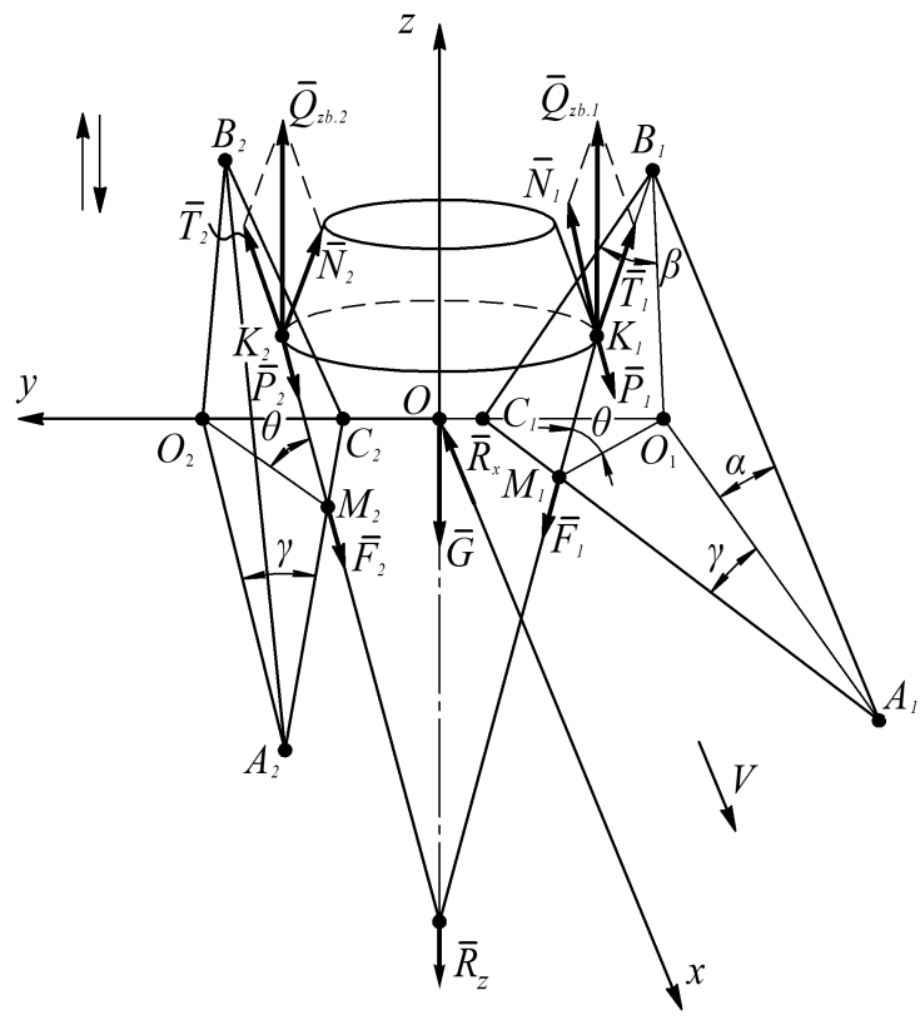

Fig. 1. Forceful interaction of the beet root with wedges of the vibrational digging tool 
During the forward movement (in the direction, shown by the arrow) with the inner surfaces, of the indicated wedges $A_{1} B_{1} C_{1}$ and $A_{2} B_{2} C_{2}$ at the corresponding two points $K_{1}$ and $K_{2}$, there is interaction of the root crop body, the proper axis of symmetry of which coincides with the axis $O_{z}$. The straight lines, drawn through the points of contact of the root crop with the planes of wedges $A_{1} B_{1} C_{1}$ and $A_{2} B_{2} C_{2}$, and points $B_{1}$ and $B_{2}$ form the corresponding points $M_{1}$ and $M_{2}$ at the intersection with the sides of the wedges $A_{1} C_{1}$ and $A_{2} C_{2}$. Thus, $\theta$ is a dihedral angle $\angle B_{1} M_{1} O_{1}$ between the bottom base $A_{1} O_{1} C_{1}$ and the working surface of wedges $A_{1} B_{1} C_{1}$, or $\angle B_{2} M_{2} O_{2}$ between the bottom base $A_{2} O_{2} C_{2}$ and the working surface of wedges $A_{2} B_{2} C_{2}$.

Let us define and show all the forces that arise as a result of the indicated interaction of the beet root with the vibrational digging tool of a share type. At the points of contact $K_{1}$ and $K_{2}$ of the root crop with the corresponding surfaces of wedges $A_{1} B_{1} C_{1}$ and $A_{2} B_{2} C_{2}$ there are vertical disturbing forces $Q_{z b .1}$ and $Q_{z b .2}$, and these forces will be equal to each other (the so-called symmetric capture of the root crop), and their values will be determined by the following expression:

$$
Q_{z b .1}=Q_{z b .2}=\frac{1}{2} Q_{z b .}=\frac{1}{2} H \cdot \sin \omega t,
$$

where $H$-amplitude of the disturbing force, $\mathrm{N}$;

$\omega$ - frequency of the disturbing force, $\mathrm{s}^{-1}$;

$t$ - current time, s.

In the forward movement of the tool at the points of contact $K_{1}$ and $K_{2}$, the driving forces $P_{1}$ and $P_{2}$ will be applied, the vectors of which are parallel to the direction of the movement of the digging tool (i.e., parallel to the $O x$ axis), and $P_{1}=P_{2}$. The totality of the action of these forces at the indicated points of contact causes normal reactions $N_{1}$ and $N_{2}$ from the surfaces of wedges $A_{1} B_{1} C_{1}$ and $A_{2} B_{2} C_{2}$, accordingly; and $T_{1}, T_{2}$ are the tangential components of the disturbing forces $Q_{z b .1}$ and $Q_{z b .2}$, respectively. Besides this, at the indicated points of contact, there are also friction forces $F_{1}, F_{2}$ acting, which arise when the root crop moves along the working surfaces of the indicated wedges.

We also assume that the module of the paired forces that arise on the corresponding planes of the wedges are equal to each other. At the centre of mass of the beet root there acts the force $G$ - the weight of the root; its bond strength (adhesion) with the soil is characterised by two forces $R_{x}$ and $R_{z}$.

Using the basic law of dynamics, we will compose a differential equation of the movement of the beet root during the process of its extraction from the soil in a vector form:

$$
m \bar{a}=\bar{N}_{1}+\bar{N}_{2}+\bar{F}_{1}+\bar{F}_{2}+\bar{P}_{1}+\bar{P}_{2}+\bar{R}_{x}+\bar{R}_{z}+\bar{G},
$$

where $m$ - mass of the root crop, $\mathrm{kg}$;

$a$ - extraction acceleration of the beet root from the soil, $\mathrm{m} \cdot \mathrm{s}^{-2}$.

Since the components of the normal reactions of the working surfaces $A_{1} B_{1} C_{1}$ and $A_{2} B_{2} C_{2}$ along the $O y$ axis are equal in magnitude and oppositely directed, the extraction of the beet root from the soil actually occurs only in plane $x O z$, and therefore the vector equation (2) is reduced to a system of two differential equations in the projections on the axis of the Cartesian coordinate system.

After determining the values of all the forces on the coordinate axis $O x$ and,$O z$ which are included into the vector equation (2), we obtain the following system of differential equations for the movement of the beet roots in projections on the coordinate axes:

$$
\left.\begin{array}{r}
m \ddot{x}=H \cos \theta \cdot \sin \theta \cdot \sin \gamma \cdot \sin \omega t+f H \cos ^{2} \theta \cdot \sin \gamma \cdot \sin \omega t+2 P_{1}-R_{x}, \\
m \ddot{z}=H \cos ^{2} \theta \cdot \sin \omega t+f H \cos \theta \cdot \sin \theta \cdot \sin \omega t-R_{z}-G .
\end{array}\right\}
$$

In such a way this system of differential equations (3) describes the process of vibrational extraction of the beet roots from the soil by a vibrational ploughshare-type digging tool moving along the coordinate axes $O x$ and $O z$, respectively.

In order to determine the law of motion of the beet root during vibrational digging along the indicated coordinate axes from the beginning of its movement to its complete extraction from the soil, we have integrated the system of differential equations (3) twice. In the final form, after two-fold 
integration of the system of differential equations (3), a law of motion of the root crop was obtained in the following form:

$$
\left.\begin{array}{c}
x=\frac{-H}{m \omega^{2}} \sin \gamma\left(\cos \theta \cdot \sin \theta+f \cos ^{2} \theta\right) \cdot \sin \omega t+\frac{t^{2}\left(2 P_{1}-R_{x}\right)}{2 m}+L_{1} t+L_{2}, \\
z=\frac{-H}{m \omega^{2}}\left(\cos ^{2} \theta-f \cos \theta \cdot \sin \theta\right) \cdot \sin \omega t-\frac{t^{2}}{2 m}\left(R_{z}+G\right)+C_{1} t+C_{2} .
\end{array}\right\}
$$

where $L_{1}, L_{2}, C_{1}, C_{2}$ - arbitrary constants.

To determine the arbitrary constants, included into system (4), the initial conditions were set, namely: at $t=0$ :

$$
\begin{gathered}
\dot{x}=0, \\
x=x_{o}, \\
\dot{z}=0, \\
z=-h_{1},
\end{gathered}
$$

where $x_{o}$ - distance of the vertical axis of the root crop from the origin of the coordinate system (point $O$ ) at the moment of time $t=0, \mathrm{~m}$;

$h_{1}$ - depth of the location of the beet root in the soil, $\mathrm{m}$.

Taking into account the initial conditions, the following values of arbitrary constants were obtained:

$$
\begin{aligned}
& C_{1}=\frac{H}{m \omega}\left(\cos ^{2} \theta-f \cos \theta \cdot \sin \theta\right) ; \\
& C_{2}=-h_{1} ; \\
& L_{1}=\frac{H}{m \omega} \sin \gamma\left(\cos \theta \cdot \sin \theta+f \cos ^{2} \theta\right) ; \\
& L_{2}=x_{o} .
\end{aligned}
$$

\section{Results and discussion}

By substituting the obtained values of the arbitrary constants (5) into expression (4), we obtain:

$$
\begin{aligned}
& x=\frac{-H}{m \omega^{2}} \sin \gamma\left(\cos \theta \cdot \sin \theta+f \cos ^{2} \theta\right) \sin \omega t+ \\
& +\frac{2 P_{1}-R_{x}}{2 m} t^{2}+\frac{H}{m \omega} \sin \gamma\left(\cos \theta \cdot \sin \theta+f \cos ^{2} \theta\right) t+x_{0}, \\
& z=-\frac{H}{m \omega^{2}}\left(\cos ^{2} \theta-f \cos \theta \cdot \sin \theta\right) \sin \omega t- \\
& -\frac{t^{2}}{2 m}\left(R_{z}+G\right)+\frac{H}{m \omega}\left(\cos ^{2} \theta-f \cos \theta \cdot \sin \theta\right) t-h_{1} .
\end{aligned}
$$

The obtained regularity determines the displacement of the centre of the mass of the beet root in the process of its extraction from the soil along the axes $O x$ and $O z$, accordingly, under the given initial conditions.

From the second equation of system (6) it is possible to determine the time of extraction of the beet root from the soil. To do this, it is necessary to substitute the value on the left side of the indicated equation and solve the resulting equation with respect to $t_{1}$.

Due to the transcendence of this equation it is impossible to obtain an analytical expression for the determination of $t_{1}$, yet it can be solved on a PC using the well-known numerical methods. The calculated value $t_{1}$ can be used to determine the performance of the root harvester when digging out sugar beet roots by vibrational digging tools of the share type. 
Using the obtained expressions (6), numerical calculations were performed on a $\mathrm{PC}$ in the MathCAD software environment with specific parameters that are included in expressions (6).

Numerical calculations were carried out at the given values of the parameters, necessary for this purpose. These values are selected according to the data given in $[13 ; 14]$ :

- mass of the root crop $m_{k}=0.9 \mathrm{~kg}$;

- length of the root crop $h_{k}=0.25 \mathrm{~m}$;

- angles of the triangular wedges of the vibrational digging tool: $\gamma=14^{\circ}, \beta=52^{\circ}$;

- coefficient of friction of steel along the surface of the root crop: $f=45$;

- forces of resistance of the soil when moving the root crop: $R_{x}=100 \mathrm{~N}, R_{z}=100 \mathrm{~N}$;

- amplitude of the disturbing force $H=500 \mathrm{~N}$;

- magnitude of the lateral driving force $P_{1}=400 \mathrm{~N}$;

- initial position of the centre of mass of the root crop along the axis $O x: x_{10}=0.2 \mathrm{~m}$.

The calculations performed for the vibration frequency of the vibrational digging tool of the share type equal to $v=10 \mathrm{~Hz}$. In [16] it is indicated that, in order to reduce the traction resistance of the machine, it is necessary to increase the vibration frequency of its working bodies to $8.8 \mathrm{~Hz}-$ this is less than the value obtained by us due to the shallower depth of travel of the working bodies. At the same time, it is noted that an increase in the vibration amplitude to $69 \mathrm{~mm}$ makes it possible to reduce the drive power by $27 \%$ [15; 16]. It should be noted that this value of the oscillation amplitude falls in the middle of the range obtained by us. There are few investigations conducted lately on the influence of the magnitude of the disturbing force upon the amplitude of oscillations when harvesting beet root crops, which, in turn, increases the relevance of this work.

On the basis of the obtained law on the motion of the centre of mass of the root crop (6) in the $x O z$ coordinate system, graphs $x=x(t)$ and $z=z(t)$ were built in the MathCAD environment (Fig. 2) in order to determine the time of extraction of the beet root from the soil during its vibrational digging.
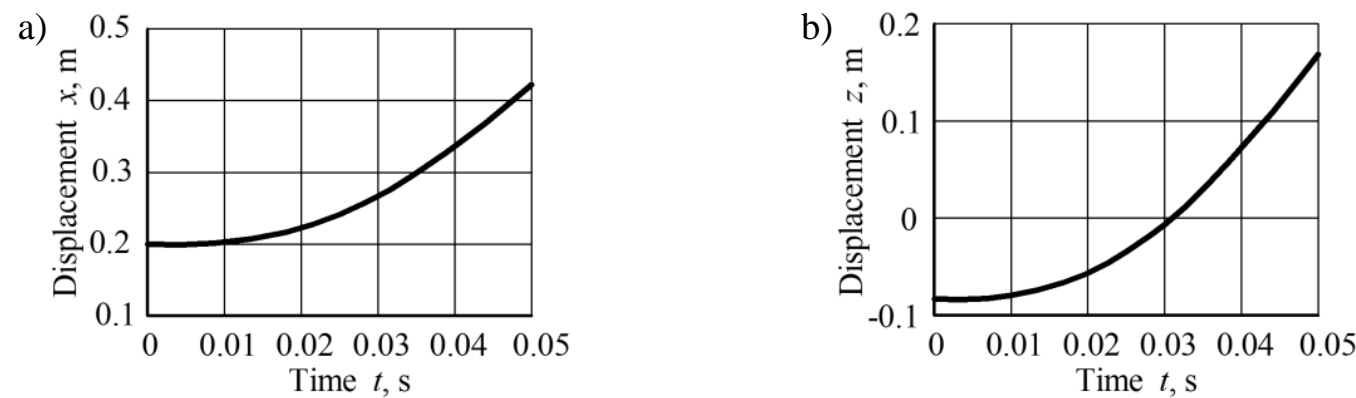

Fig. 2. Graphs of dependences of the displacement of the centre of mass of the root crop along the axes $O x$ (a) and $O z$ (b) upon the time when the root crop is directly dug out from the soil $\left(H=500 \mathrm{~N}, P_{1}=400 \mathrm{~N}, R_{x}=100 \mathrm{~N}, R_{z}=100 \mathrm{~N}, v=10 \mathrm{~Hz}\right)$

As it is evident from the graph, the extraction time of the beet root from the soil $(z=0)$ is $0.032 \mathrm{~s}$. We have also calculated the displacement of the centre of mass of the beet root along the axis $O z$ until its complete extraction from the soil, depending upon the change in the amplitude of the disturbing force, and graphs $z=z(H, t)$ have been obtained at $P_{1}=$ const, and upon the change in the lateral driving force $z=z\left(P_{1}, t\right)$ at $H=$ const.

Fig. 3 shows the surface and the contour graph of the function $z=z(H, t)$, when the amplitude of the disturbing force changes within the range $=100 \ldots 700 \mathrm{~N}$ (for constant values of the lateral driving force $P_{1}=400 \mathrm{~N}$ and the vibration frequency $v=10 \mathrm{~Hz}$ ).

As it can be seen from the above graph, when the amplitude of the disturbing force changes in the range of 100-700 N, the time for extracting the beet root from the soil varies within 0.053-0.028 s.

Fig. 4 presents the surface and the contour graph of the function, when the lateral driving force changes within the range of 100-700 $\mathrm{N}$ (for constant values of the amplitude of the disturbing force $=500 \mathrm{~N}$ and vibration frequency $H=10 \mathrm{~Hz}$ ). 
a)

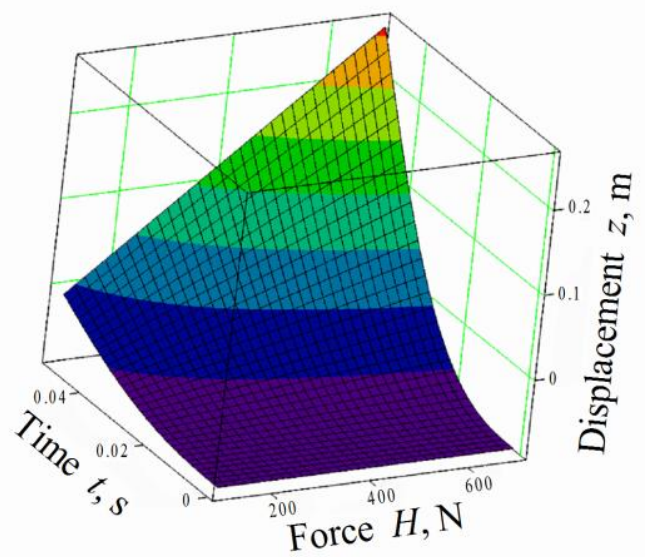

b)

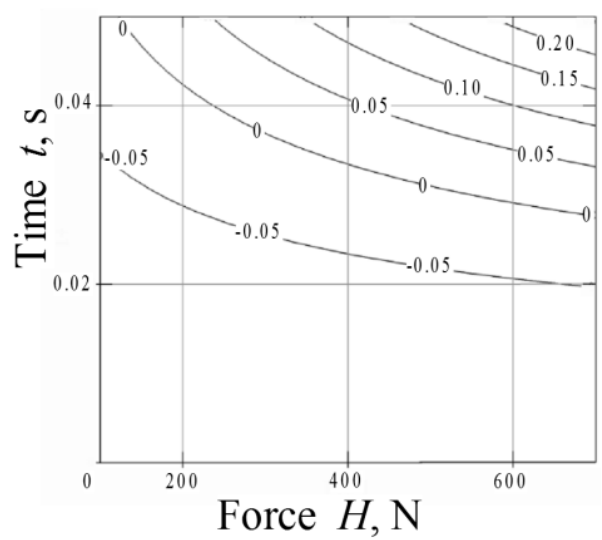

Fig. 3. Surface (a) and contour graph (b) of function $z=z(H, t)$ with a change in the amplitude of the disturbing force within the range $H=100-700 \mathrm{~N}\left(P_{1}=400 \mathrm{~N}, v=10 \mathrm{~Hz}\right)$

a)

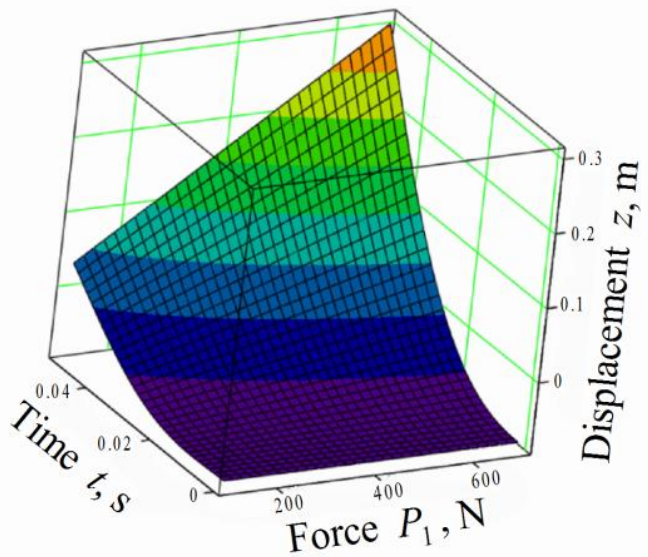

b)

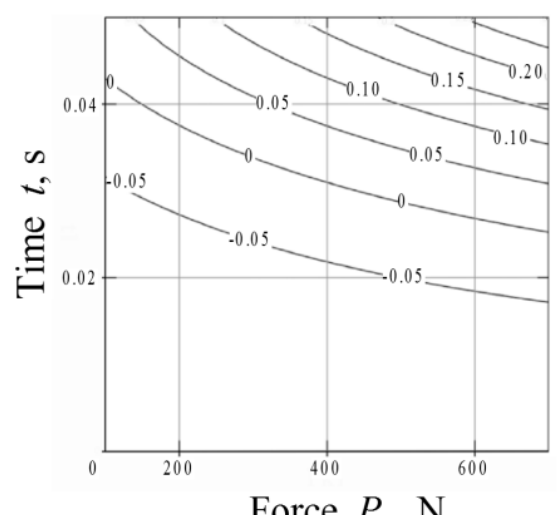

Force $P_{1}, \mathrm{~N}$

Fig. 4. Surface (a) and contour graph (b) of function $z=z\left(P_{1}, t\right)$ with a change in the lateral driving force within the range $P_{1}=100 \ldots 700 \mathrm{~N}(H=500 \mathrm{~N}, v=10 \mathrm{~Hz})$

As evident from the above graph, when the lateral driving force changes within the range of 100$700 \mathrm{~N}$, the time for extracting the beet root from the soil varies within 0.043-0.026 s.

In [8] studies of the influence of the speed of the movement upon the drive power of a machine with vibrating digging tools were carried out, but this was done without changing the parameters of the vibration process and disclosing the reasons for changing the traction resistance. Also, much attention is paid to determination of the loss of the root crops after the passage of the beet-digging machine, depending on the speed of its movement; but at a constant frequency and amplitude of oscillations of the working tool with increasing speed we will get a decrease in the time and number of interactions of the working tool with the body of the root crop, which is not desired.

In work [5] the theoretical foundations of creating a machine for vibrational digging of root crops were developed without studying the influence of the magnitude of the disturbing force and the frequency of its application upon the vibrational displacement of the working tool, which was carried out in our research.

Consequently, application of the obtained research results can be aimed at increasing the efficiency of vibrational digging of root crops, while reducing the energy consumption for the vibration process itself.

The structural diagram of the vibrational digging tool is shown in Fig. 5.

The results obtained during the theoretical investigations implemented in an improved vibrational digging tool have shown the performance characteristics of this technological process, which is superior to that of the best world analogues. 


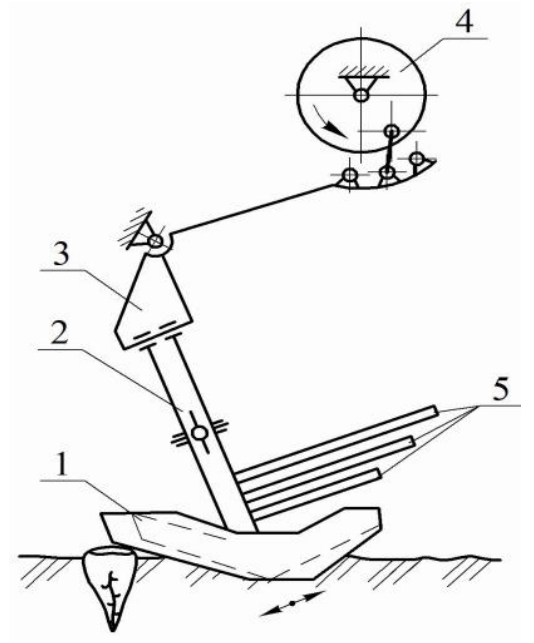

Fig. 5. Advanced vibrational digging tool for beetroot crops: 1 - digging ploughshares; 2 - legs; 3 - mechanism for regulating the size of the working channel, formed by the digging shares; 4 - vibrational drive; 5 - guides of the dug out roots

\section{Conclusions}

1. A new computational mathematical model of vibrational digging of the beet root from the soil has been built, as a result of which new analytical dependences of the movement of the beet root in time and in the direction of the forward movement of the vibratory digging tool have been obtained, as well as when it is moving upward in the extraction process from the soil, taking into account its design and kinematic parameters.

2. The numerical calculations, executed by means of a PC, showed that the time for complete extraction of the beet root from the soil is $0.032 \mathrm{~s}$ at the vibration frequency of the tool of $10 \mathrm{~Hz}$ and an amplitude of the disturbing force equal to $500 \mathrm{~N}$.

3. New designs of vibrational digging tools have been developed, implementing the obtained parameters of the considered vibrational process, allowing more efficient extraction of the sugar beet roots from the soil.

\section{References}

[1] Vilde A. Development of technologies and machinery for production of sugar beet in Latvia. Proceedings of the conference "Safe and economical agricultural technologies" (25-26 July, 2002, Priekuli, Latvia), 2002. pp. 62-66.

[2] Merkes R. 50 Jahre Prodaktionstechnik im Zuckerr. Benbau in Deutchland. Zuckerr., No 4, 2001, pp. 214-217,

[3] Gruber, W. Trends in sugar beet harvesting. Landtechnik, 60 (6), 2005, pp. 320-321.

[4] Bulgakov V., Ivanovs S., Adamchuk V., Boris A. Mathematical model for determination of losses of sugar bearing-mass when sugar beet tops are removed. Engineering for Rural Development, Vol. 14, 2015, pp. 441-451.

[5] Василенко П.М., Погорелый Л.В., Брей В.В. Вибрационный способ выкапывания корнеплодов. Механизация и электрификация социалистического сельского хозяйства (Vibrating method of picking up root crops. Mechanization and electrification of agriculture), Vol.2, 1970, pp. 9-13. (In Russian)

[6] Hoffmann, C.M. Sugar beet from field clamps - harvest quality and storage loss. Zuckerindustrie, 143 (11), 2018, pp. 639-647.

[7] Погорелый Л.В. Свеклоуборочные машины: история, конструкция, теория, прогноз (Beet Harvesting Machines: history, design, theory, forecast). Kyiv, 2004, 232 p. (In Ukrainian).

[8] Adamchuk V. V., Bulgakov V. M., Holovach I. V., Ignatiev Ye. I. Experimental research on vibrational digging-up of sugar beet. Agricultural science and practice. 2018. Vol.1., pp. 30-41 
[9] Bulgakov V., Ivanovs S., Ruzhylo Z., Golovach I. Theoretical investigations in cleaning sugar beet heads from remnants of leaves by cleaning blade. Engineering for Rural Development, Volume 15, 2016, pp.1090-1097.

[10] Ukrainian patent UA85123. Vibrating digging tool. Authors: Bulgakov V., Litvinov O., Holovach I. Kyiv, 2007.

[11]Василенко П.М. Введение в земледельческую механику (Introduction to agricultural mechanics). 1996, Kiev, 252 p. (in Ukrainian)

[12] Kibble T., Berkshire F. Classical Mechanics (5th ed.). Imperial College Press, 2004.

[13] Bentini, M., Caprara, C., Rondelli, V. Mechanical properties of sugar beet roots. Transactions of the American Society of Agricultural Engineers, 48 (4), 2005, pp. 1429-1439.

[14] Хелемендик Н.M. Повышение механико-технологической эффективности трудоемких процессов в свекловодстве (Increasing the Mechanical and Technological Efficiency of the Labour Consuming Processes in Beat Growing). Ternopol, 1996. 48 p. (In Ukrainian).

[15] Radite P.A.S., Hermawan W., Rizkianda A.B., Crosby H.B. Experimental investigation on the application of vibration to reduce draft requirement of subsoiler. International Agricultural Engineering Journal, 19(1), 2010, pp. 31-38.

[16] Shahgoli G., Fielke J., Desbiolles J., Saunders C. Optimising oscillation frequency in oscillatory tillage. Soil and tillage research, 106(2), 2010, pp. 202-210. 